\title{
KARAKTERISTIK RANK MATRIKS FUZZY
}

\author{
MUTIARA NOVITA SARI, NOVA NOLIZA BAKAR, MONIKA RIANTI HELMI \\ Program Studi Matematika, \\ Fakultas Matematika dan Ilmu Pengetahuan Alam, Universitas Andalas, \\ Kampus UNAND Limau Manis Padang, Indonesia. \\ email : mutiaranovitasani@gmail.com
}

\begin{abstract}
Abstrak. Tulisan ini membahas tentang karakteristik rank dari matriks fuzzy dimana dalam menentukan rank pada matriks fuzzy berbeda dengan matriks biasa karena operasi penjumlahan dan perkalian pada matriks fuzzy menggunakan operasi maks-min yang dikenal dengan aljabar fuzzy maks-min [0,1]. Karakteristik rank yang dibahas pada tulisan ini adalah faktorisasi rank fuzzy, faktorisasi rank baris, faktorisasi rank kolom, dan faktorisasi rank.
\end{abstract}

Kata Kunci: Aljabar Fuzzy Maks-min, Ruang Baris, Ruang Kolom, Rank Fuzzy, Rank Baris, Rank Kolom

$\begin{array}{lll}\text { Diterima } & : & \text { 29 November } 2018 \\ \text { Direvisi } & : & 3 \text { Desember } 2018 \\ \text { Dipublikasikan } & : & 30 \text { Desember } 2018\end{array}$

\section{Pendahuluan}

Konsep himpunan fuzzy dikembangkan dalam bentuk matriks yang kemudian dikenal dengan nama matriks fuzzy oleh Thomson pada tahun 1977, kemudian teori dari matriks fuzzy dikembangkan lagi oleh Kim and Roush[2]. Matriks fuzzy juga memiliki perbedaan dengan matriks biasa dimana operasi-operasi pada matriks fuzzy menggunakan operasi max-min sehingga dalam menentukan rank di matriks fuzzy juga berbeda. Rank baris dalam matriks fuzzy didefinisikan sebagai jumlah anggota dalam himpunan pembangun minimal dari ruang baris matriks fuzzy [1]. Sedangkan rank kolom adalah rank baris dari transpos matriks fuzzy. Rank merupakan konsep mendasar untuk pengembangan teori matriks fuzzy. Tulisan ini akan membahas mengenai karakteristik rank matriks fuzzy.

\section{Tinjauan Teori}

\subsection{Aljabar Fuzzy}

Definisi 2.1. [1] Aljabar fuzzy adalah sistem matematika $(F,+,$.$) dengan operasi +$ dan - yang didefinisikan pada himpunan $F$, dimana untuk setiap a, $b, c \in F$ berlaku:

(1) $a+a=a$ dan $a \cdot a=a$,

(2) $a+b=b+a$ dan $a \cdot b=b \cdot a$,

(3) $a+(b+c)=(a+b)+c$ dan $a \cdot(b \cdot c)=(a \cdot b) \cdot c$, 
(4) $a+(a \cdot b)=a$ dan $a \cdot(a+b)=a$,

(5) $a \cdot(b+c)=(a \cdot b)+(a \cdot c)$ dan $a+(b \cdot c)=(a+b) \cdot(a+c)$,

(6) terdapat $0 \in F$ sehingga $a+0=a$ dan $a \cdot 0=0$,

(7) terdapat $1 \in F$ sehingga $a+1=1$ dan $a \cdot 1=a$.

Berikut contoh dari aljabar fuzzy. Misalkan himpunan $\mathcal{F}=[0,1]$ dengan operasi $(+, \cdot)$ didefinisikan sebagai $: a+b=\operatorname{maks}\{a, b\}$ dan $a \cdot b=\min \{a, b\}$ untuk semua $a, b \in[0,1]$. Ini disebut aljabar fuzzy maks-min.

\subsection{Matriks Fuzzy}

Matriks fuzzy adalah matriks yang entri-entrinya merupakan aljabar fuzzy maksmin $[0,1]$. Misalkan fuzzy $\mathcal{F}_{m n}$ adalah notasi untuk himpunan matriks-matriks berukuran $m \times n$ atas aljabar fuzzy $\mathcal{F}=[0,1]$. Elemen-elemen dari $\mathcal{F}_{m n}$ disebut matriks fuzzy. Matriks fuzzy juga merupakan suatu aljabar fuzzy. Berikut akan diberikan definisi-definisi pada matriks fuzzy sebagai pendukung dan pengimplementasian pada bab selanjutnya.

Definisi 2.2. [3] Matriks $A=\left[a_{i j}\right]$ dikatakan matriks fuzzy, jika $a_{i j} \in \mathcal{F}=[0,1]$, untuk setiap $i, j \in \mathbb{R}$.

Definisi 2.3. [1] Misalkan $A=\left[a_{i j}\right] \in \mathcal{F}_{m n}$ dan $B=\left[b_{i j}\right] \in \mathcal{F}_{m n}$, maka $A+B=$ $\left[\right.$ maks $\left.\left\{a_{i j}, b_{i j}\right\}\right] \in \mathcal{F}_{m n}$ merupakan penjumlahan dari $A$ dan $B$.

Definisi 2.4. [1] Misalkan $A=\left[a_{i j}\right] \in \mathcal{F}_{m n}$ dan $c \in \mathcal{F}$, maka perkalian fuzzy yaitu perkalian skalar dengan skalar dibatasi pada $\mathcal{F}$ didefinisikan sebagai $c A=$ $\left[\min \left\{c, a_{i j}\right\}\right] \in \mathcal{F}_{m n}$.

Definisi 2.5. [1] Misalkan $A=\left[a_{i j}\right] \in \mathcal{F}_{m n}$ dan $B=\left[b_{i j}\right] \in \mathcal{F}_{m n}$, maka $A \cdot B=$ $\left[\sum_{k=1}^{p} a_{i k} \cdot b_{k j}\right]=\left[\operatorname{maks}_{k}\left\{\min \left\{a_{i k}, b_{k j}\right\}\right\}\right] \in \mathcal{F}_{m n}$. Hasil dari AB terdefinisi jika dan hanya jika jumlah kolom $A$ sama dengan jumlah baris $B$.

Definisi 2.6. [1] Misalkan $A=\left[a_{i j}\right] \in \mathcal{F}_{m n}$, transpos dari matriks $A$ adalah hasil dari pertukaran baris-baris dengan kolom-kolom pada A yang dinotasikan dengan $A^{T}$.

Matriks fuzzy dengan pengoperasian maks-min merupakan bagian terpenting pada pembahasan kali ini. Baris-baris pada matriks fuzzy merupakan vektor fuzzy, begitu juga dengan kolom-kolomnya. Untuk itu, akan dibahas mengenai ruang vektor atas aljabar fuzzy.

\subsection{Ruang Vektor atas Aljabar Fuzzy}

Ruang vektor atas aljabar fuzzy adalah ruang vektor yang elemen-elemennya memenuhi sifat-sifat aljabar fuzzy. Berikut akan diberikan definisi-definisi mengenai vektor fuzzy sebagai materi pendukung pada pembahasan.

Definisi 2.7. [1] Misalkan $V_{n}$ merupakan himpunan n-tuples $\left(x_{1}, x_{2}, \cdots, x_{n}\right)$ atas $\mathcal{F}$. Elemen-elemen dari $V_{n}$ disebut vektor fuzzy berdimensi $n$. Operasi penjumlahan 
dan perkalian pada $V_{n}$ didefinisikan sebagai berikut :

Untuk $x=\left(x_{1}, x_{2}, \cdots, x_{n}\right)$ dan $y=\left(y_{1}, y_{2}, \cdots, y_{n}\right)$ di $V_{n}$ berlaku

$x+y=\left(x_{1}+y_{1}, x_{2}+y_{2}, \ldots, x_{n}+y_{n}\right)$ dan $a x=\left(a x_{1}, a x_{2}, \cdots\right.$, ax $\left.x_{n}\right)$ untuk suatu $a$ $\in \mathcal{F}$

Sistem $V_{n}$ dengan operasi penjumlahan dan perkalian fuzzy disebut ruang vektor fuzzy.

Definisi 2.8. [1] Sebuah subruang dari $V_{n}$ adalah subhimpunan $W$ dari $V_{n}$ sedemikian sehingga $\boldsymbol{O} \in W$ untuk setiap $x, y \in W, x+y \in W$.

\section{Contoh 2.9.}

Misalkan $W=\{(0,0,0),(1,0,0),(0,1,0),(0,0,1),(1,1,0),(0,1,1),(1,0,1),(1,1,1)\}$, maka $W$ merupakan subruang dari $V_{3}$.

Definisi 2.10. [1] Kombinasi linier dari elemen-elemen himpunan $S$ adalah jumlah berhingga $\sum a_{i} v_{i}$ dimana $v_{i} \in S$ dan $a_{i} \in \mathcal{F}$. Himpunan dari semua kombinasi linier dari elemen-elemen $S$ disebut pembangun dari $S$ dan dinotasikan dengan $<S>$.

\section{Karakteristik Rank Matriks Fuzzy}

Rank merupakan salah satu konsep dasar untuk pengembangan teori matriks fuzzy. Pada rank matriks $f u z z y$, rank kolom dan rank baris dari suatu matriks $f u z z y$ tidak sama. Selain itu, ada juga konsep rank yang disebut rank $f u z z y$. Ruang baris yang dinotasikan dengan $\mathbb{R}(A)$, ruang kolom dinotasikan dengan $\mathbb{C}(A)$, rank baris dan rank kolom masing masing dinotasikan dengan $\rho_{r}(A)$ dan $\rho_{c}(A)$.

Definisi 3.1. [1] Ruang baris yang dinotasikan dengan $\mathbb{R}(A)$ dari matriks $A$ berukuran $m \times n$ merupakan subruang dari $V_{n}$ yang dibangun oleh baris -baris pada matriks $A$. Rank baris yang dinotasikan dengan $\rho_{r}(A)$ merupakan jumlah terkecil dari himpunan yang membangun $\mathbb{R}(A) . \mathbb{C}(A)=\mathbb{R}\left(A^{T}\right)$ dan $\rho_{c}(A)=\rho_{r}\left(A^{T}\right)$.

Untuk matriks berhingga $A, \rho_{r}(A)$ adalah jumlah maksimum baris-baris yang bebas linier pada matriks $A$.

Teorema 3.2. [1] Untuk $A, B \in \mathcal{F}_{m n}$ berlaku

(1) $\mathbb{R}(B) \subseteq \mathbb{R}(A)$ jika dan hanya jika $B=X A$ untuk suatu $X \in \mathcal{F}_{m}$.

(2) $\mathbb{C}(B) \subseteq \mathbb{C}(A)$ jika dan hanya jika $B=A Y$ untuk suatu $Y \in \mathcal{F}_{n}$.

Definisi 3.3. [1] Misalkan $A \in \mathcal{F}_{m n}$. Rank fuzzy $\rho_{f}(A)$ adalah bilangan bulat terkecil $t$ sedemikian sehingga $A=B C$, dimana $B \in \mathcal{F}_{m t}$ dan $C \in \mathcal{F}_{t n}$. Faktorisasi tersebut dinamakan faktorisasi rankfuzzy

Teorema 3.4. [1] Misalkan $A \in \mathcal{F}_{m n}$ dengan $\rho_{r}(A)=r$, maka terdapat matriks $B \in \mathcal{F}_{m r}$ dan $C \in \mathcal{F}_{r n}$ sedemikian sehingga $\rho_{r}(A)=\rho_{r}(C)=r \operatorname{dan} A=B C$. Faktorisasi ini disebut faktorisasi rank baris dari matriks $A$.

Teorema 3.5. [1] Misalkan $A \in \mathcal{F}_{m n}$ dengan $\rho_{c}(A)=s$, maka terdapat matriks $B \in \mathcal{F}_{m s}$ dan $C \in \mathcal{F}_{s n}$ sedemikian sehingga $\rho_{c}(A)=\rho_{c}(B)=s$ dan $A=B C$. Faktorisasi ini disebut faktorisasi rank kolom matriks $A$. 
Teorema 3.6. [1] Misalkan $A \in \mathcal{F}_{m n}$ dengan $\rho(A)=\rho_{r}(A)=\rho_{c}(A)=r$, maka terdapat matriks $B \in \mathcal{F}_{m r}$ dan $C \in \mathcal{F}_{r n}$ sedemikian sehingga $\rho(A)=\rho_{c}(B)=$ $\rho_{r}(C)=r$ dan $A=B C$. Faktorisasi ini disebut faktorisasi rank matriks $A$.

Bukti. Berdasarkan pembuktian Teorema ??, terdapat $B \in \mathcal{F}_{m r}$ dan $C \in \mathcal{F}_{r n}$ sedemikian sehingga $\rho_{r}(A)=\rho_{r}(C)=r$ dan berdasarkan Teorema 3.5 terdapat $B \in \mathcal{F}_{m s}$ dan $C \in \mathcal{F}_{s n}$ sedemikian sehingga $\rho_{c}(A)=\rho_{c}(B)=s$, sehingga $\rho_{r}(A)=r$ dengan $B \in \mathcal{F}_{m r}$ dan $C \in \mathcal{F}_{r n}$, maka $\rho_{r}(C)=r$ dan $\rho_{c}(A)=r$ dengan $B \in \mathcal{F}_{m r}$ dan $C \in \mathcal{F}_{r n}$, maka $\rho_{c}(B)=r$. Akibatnya $\rho_{r}(A)=\rho_{c}(A)=\rho_{c}(B)=\rho_{r}(C)=r$. Oleh karena itu, Teorema 3.6 terbukti.

Teorema 3.7. [1] Misalkan $A \in \mathcal{F}_{m n}$. Rank fuzzy $\rho_{f}(A)$ memenuhi sifat-sifat berikut :

1. $\rho_{f}(A) \leq \min \left\{\rho_{r}(A), \rho_{c}(A)\right\}$.

2. $\rho_{f}(P A Q) \leq \rho_{f}(A)$, untuk setiap $P \in \mathcal{F}_{p m}$ dan $Q \in \mathcal{F}_{n q}$.

\section{Bukti.}

(1) Misalkan $A \in \mathcal{F}_{m n}$ dengan $\rho_{r}(A)=r$. Maka berdasarkan Teorema 3.4, A mempunyai faktorisasi rank baris, yakni $A=B C$, dengan $\rho_{r}(A)=\rho_{r}(C)=$ $r, B \in \mathcal{F}_{m r}, C \in \mathcal{F}_{r n}$. Dengan menggunakan Definisi 3.3, maka $\rho_{f}(A) \leq \rho_{r}(A)$. Kemudian dari Teorema 3.5 diketahui bahwa $\rho_{c}(A)=\rho_{c}(B)=r$. Karena $\rho_{f}(A)$ merupakan bilangan bulat terkecil $t$ sedemikian sehingga $A=B C$, maka $\rho_{f}(A) \leq \rho_{c}(A)$. Oleh karena itu, $\rho_{f}(A) \leq \min \left\{\rho_{r}(A), \rho_{c}(A)\right\}$.

(2) Misalkan $\rho_{f}(A)=t$, maka dari Definisi 3.3 diperoleh $t$ merupakan bilangan bulat terkecil sedemikian sehingga $A=B C$ adalah faktorisasi rank fuzzy dari A dengan $B \in \mathcal{F}_{m t}, C \in \mathcal{F}_{t n}$ Kemudian ambil $P \in \mathcal{F}_{p m}, Q \in \mathcal{F}_{n q}$, maka $P A Q=$ $P(B C) Q=(P B)(C Q)$. Misalkan $P B=V$ dan $C Q=W$, maka $P A Q=V W$, dimana $V \in \mathcal{F}_{p t}$ dan $W \in \mathcal{F}_{t q}$, sehingga diperoleh sebuah faktorisasi untuk $P A Q$. Karena $\rho_{f}(A)=t$, maka berdasarkan Definisi 3.3 diperoleh $\rho_{f}(P A Q) \leq$ t. Akibatnya diperoleh

$$
\begin{array}{r}
\rho_{f}(P A Q) \leq \rho_{f}(A)=t, \\
\rho_{f}(P A Q) \leq \rho_{f}(A) .
\end{array}
$$

Akibat 3.8. [1] Misalkan $A \in \mathcal{F}_{m n}$ dan $B \in \mathcal{F}_{n p}$, maka berlaku hal berikut: 1 . $\rho_{f}(A B) \leq \min \left\{\rho_{r}(A), \rho_{r}(B)\right\}$.

2. $\rho_{f}(A B) \leq \min \left\{\rho_{c}(A), \rho_{c}(B)\right\}$.

3. $\rho_{f}(A B) \leq \min \left\{\rho_{r}(A), \rho_{r}(B), \rho_{c}(A), \rho_{c}(B)\right\}$.

Akibat 3.9. [1] Misal $A \in \mathcal{F}_{m n}, B \in \mathcal{F}_{n p}$,

(1) Jika $\rho_{r}(A B)=\rho_{f}(A B) \operatorname{maka} \rho_{r}(A B) \leq \min \left\{\rho_{r}(A), \rho_{r}(B)\right\}$.

(2) Jika $\rho_{c}(A B)=\rho_{f}(A B)$, maka $\rho_{c}(A B) \leq \min \left\{\rho_{c}(A), \rho_{c}(B)\right\}$.

\section{Bukti.}


(1) Misal $A \in \mathcal{F}_{m n}, B \in \mathcal{F}_{n p}, \rho_{r}(A B)=\rho_{f}(A B)$, kemudian berdasarkan Teorema 3.7 diketahui bahwa

$$
\rho_{f}(A B) \leq \rho_{f}(A) \leq \rho_{r}(A) \text { dan } \rho_{f}(A B) \leq \rho_{f}(B) \leq \rho_{r}(B) .
$$

Karena $\rho_{r}(A B)=\rho_{f}(A B)$, maka $\rho_{r}(A B) \leq \rho_{r}(A)$ dan $\rho_{r}(A B) \leq \rho_{r}(B)$. Akibatnya diperoleh $\rho_{f}(A B) \leq \min \left\{\rho_{r}(A), \rho_{r}(B)\right\}$.

(2. Misal $A \in \mathcal{F}_{m n}, B \in \mathcal{F}_{n p}, \rho_{c}(A B)=\rho_{f}(A B)$, kemudian berdasarkan Teorema 3.7 diketahui bahwa

$$
\rho_{f}(A B) \leq \rho_{f}(A) \leq \rho_{c}(A) \text { dan } \rho_{f}(A B) \leq \rho_{f}(B) \leq \rho_{c}(B) .
$$

Karena $\rho_{c}(A B)=\rho_{f}(A B)$, maka $\rho_{c}(A B) \leq \rho_{c}(A)$ dan $\rho_{c}(A B) \leq \rho_{c}(B)$. Akibatnya diperoleh $\rho_{f}(A B) \leq \min \left\{\rho_{c}(A), \rho_{c}(B)\right\}$.

Akibat 3.10. [1] Untuk $A \in \mathcal{F}_{m n}$, berlaku :

1. $\rho_{f}\left(A A^{T}\right) \leq \min \left\{\rho_{r}(A), \rho_{c}(A)\right\}$.

2. $\rho_{f}\left(A^{T} A\right) \leq \min \left\{\rho_{r}(A), \rho_{c}(A)\right\}$.

\section{Kesimpulan}

Rank merupakan salah satu konsep dasar untuk pengembangan teori matriks fuzzy. Pada rank matriks $f u z z y$, rank kolom dan rank baris dari suatu matriks $f u z z y$ tidak sama. Selain itu, ada juga konsep rank yang disebut rank fuzzy. Berikut diperoleh beberapa karaterikstik rank dari matriks fuzzy, diantaranya :

(1) Untuk $A, B \in \mathcal{F}_{m n}$ berlaku

(a) $\mathbb{R}(B) \subseteq \mathbb{R}(A)$ jika dan hanya jika $B=X A$ untuk suatu $X \in \mathcal{F}_{m}$.

(b) $\mathbb{C}(B) \subseteq \mathbb{C}(A)$ jika dan hanya jika $B=A Y$ untuk suatu $Y \in \mathcal{F}_{n}$.

(2) Misalkan $A \in \mathcal{F}_{m n}$ dengan $\rho_{r}(A)=r$, maka terdapat matriks $B \in \mathcal{F}_{m r}$ dan $C \in \mathcal{F}_{r n}$ sedemikian sehingga $\rho_{r}(A)=\rho_{r}(C)=r$ dan $A=B C$. Faktorisasi ini disebut faktorisasi rank baris dari matriks $A$.

(3) Misalkan $A \in \mathcal{F}_{m n}$ dengan $\rho_{c}(A)=s$, maka terdapat matriks $B \in \mathcal{F}_{m s}$ dan $C \in \mathcal{F}_{s n}$ sedemikian sehingga $\rho_{c}(A)=\rho_{c}(B)=s$ dan $A=B C$. Faktorisasi ini disebut faktorisasi rank kolom matriks $A$.

(4) Misalkan $A \in \mathcal{F}_{m n}$ dengan $\rho(A)=\rho_{r}(A)=\rho_{c}(A)=r$, maka terdapat matriks $B \in \mathcal{F}_{m r}$ dan $C \in \mathcal{F}_{r n}$ sedemikian sehingga $\rho(A)=\rho_{c}(B)=\rho_{r}(C)=r$ dan $A=B C$. Faktorisasi ini disebut faktorisasi rank matriks $A$.

(5) Misalkan $A \in \mathcal{F}_{m n}$. Rank fuzzy $\rho_{f}(A)$ memenuhi sifat-sifat berikut :

1. $\rho_{f}(A) \leq \min \left\{\rho_{r}(A), \rho_{c}(A)\right\}$.

2. $\rho_{f}(P A Q) \leq \rho_{f}(A)$, untuk setiap $P \in \mathcal{F}_{p m}$ dan $Q \in \mathcal{F}_{n q}$.

(6) Misal $A \in \mathcal{F}_{m n}, B \in \mathcal{F}_{n p}$, berlaku :

1.Jika $\rho_{r}(A B)=\rho_{f}(A B)$ maka $\rho_{r}(A B) \leq \min \left\{\rho_{r}(A), \rho_{r}(B)\right\}$.

2.Jika $\rho_{c}(A B)=\rho_{f}(A B)$, maka $\rho_{c}(A B) \leq \min \left\{\rho_{c}(A), \rho_{c}(B)\right\}$.

(7) Untuk $A \in \mathcal{F}_{m n}$, berlaku :

1. $\rho_{f}\left(A A^{T}\right) \leq \min \left\{\rho_{r}(A), \rho_{c}(A)\right\}$

2. $\rho_{f}\left(A^{T} A\right) \leq \min \left\{\rho_{r}(A), \rho_{c}(A)\right\}$ 
38 Mutiara Novita Sani dkk

\section{Ucapan Terima kasih}

Penulis mengucapkan terima kasih kepada Ibu Dr. Yanita, Ibu Izzati Rahmi HG M,Si, dan Ibu Riri Lestari M,Si yang telah memberikan masukan dan saran dalam penyempurnaan penulisan artikel ini.

\section{Daftar Pustaka}

[1] Meenakshi, A.R. 2008. Fuzzy Matrix Theory and Applications, MJP Publishers, India

[2] Kim,K.H dan Roush, F.W., Generalized fuzzy matrices, Fuzzy Sets and Systems 4: $293-315$ (1980)

[3] Sidky, F.I and E.G. Enam. 1992. Some Remarks on Section of a Fuzzy Matrix, Journal of King Abdulaziz University. Sci 4: 145 - 155

[4] M.G. Thomson. 1977. Convergence of power of a fuzzy matrix, Journal of Mathematical Analysis and Aplications, 57: 476 - 480 